\title{
ASPECTOS DE LA PRÁCTICA MUSICAL ESPAÑOLA EN EL SIGLO XVII: VOCES Y EJECUCIÓN VOCAL
}

\author{
Luis Antonio GonZÁlez MARÍN \\ Departamento de Musicología, CSIC
}

\begin{abstract}
This article stresses again some elements of historical musical practice, and constitutes a review and a new reflection on the materials related to the conditions and conventions of the execution of vocal music in the 17th century in Spain, some of them already published.
\end{abstract}

\section{Resumen}

Este artículo incide de nuevo en algunos elementos de la práctica musical histórica, y constituye una revisión y nueva reflexión sobre materiales, algunos de ellos ya publicados, relativos a las condiciones y convenciones de la ejecución de música vocal en la España del siglo XVII.

Este trabajo propone una reflexión sobre diferentes aspectos relacionados con el uso de las voces en la música española del siglo XVII: las diversas voces masculinas y femeninas, así como la utilización separada y conjunta de unas y otras en distintas formaciones; las tesituras y extensiones, sobre la base de los diapasones en uso y la convención de las claves transpositoras; el nivel de exigencia técnica, atestiguado por ejercicios de oposición, por comentarios críticos y por la propia música; la ornamentación vocal, a través de fuentes musicales hasta ahora desconocidas; la declaración de la letra, esto es, la adecuación del texto a la música y la dicción expresiva. Dicha reflexión, que forma parte de un trabajo en curso sobre la interpretación de la música española del siglo XVII, amplía nuestro conocimiento sobre la propia música, cuyas perspectivas de ejecución influían notablemente en la composición, y aporta nuevas evidencias de cara a la interpretación moderna de la música del siglo XVII.

A modo de índice o guión previo, un trabajo de las características del que aquí se anuncia se propone reflexionar sobre las siguientes líneas:

1. Qué voces e instrumentos se utilizaban, dónde, cuándo, cómo y con qué funciones.

2. Qué sabemos de las técnicas vocales e instrumentales.

3. Qué diapasón y qué sistemas de afinación estaban en uso y por qué razones. 
4. Hasta dónde llegaba el grado de sujeción a lo escrito o de improvisación (en el continuo, la ornamentación, la ejecución al improviso de piezas completas...).

5. Qué pertenece a la composición y qué a la ejecución, en los diferentes géneros (música de iglesia, música teatral...).

6. Finalmente, dónde termina la intuición justificable, dónde cabe la libertad del intérprete, dónde están los límites de lo lícito en nuestra recreación de la música del siglo XVII.

Lógicamente, dentro de un ámbito musical esencialmente vocal, los primeros aspectos a tratar tienen que ver con el uso de las voces, y a ello se dedica este primer avance. Partimos de la información que nos ofrecen las propias fuentes musicales y numerosos testimonios escritos que aluden a las exigencias que se deben contemplar a la hora de examinar una voz o que tratan de las excepcionales cualidades de tal o cual cantante (a veces, incluso los mismos textos de villancicos ofrecen datos). Estas informaciones a menudo son más abundantes y más precisas que lo que pudiera pensarse; basten dos ejemplos: por un lado, las partichelas suelen contener anotaciones y pequeños detalles valiosos (los nombres de cantores, pequeñas ayudas verbales o mediante signos sobre el modo de atacar un pasaje, advertencias, avisos); por otro lado, los tratados de música práctica (Cerone, Lorente, Nassarre... ${ }^{1}$ ), para los cuales prefiero no utilizar la terminología hoy corriente de "teóricos musicales", pues sus autores son músicos prácticos en ejercicio, y en sus textos, al margen de las inevitables introducciones y alusiones especulativas, necesarias para garantizar la defensa de la ingenuidad de la música, ars o ciencia, separada de los oficios manuales - lo mismo sucede en ese tiempo en relación con la pintura, es una cuestión puramente de prestigio social-, se habla de música práctica, se dan normas para la práctica —de composición y de ejecución-y se refleja la praxis musical de la época, lo que el tratadista mismo está viendo, escuchando y practicando como compositor y como ejecutante. En cualquiera de estos tratados, la sabiduría allí recogida, fruto de lecturas obligadas, estudios, aprendizaje de maestros y de la propia experiencia práctica de cada tratadista, se manifiesta en tres niveles distintos aunque íntimamente vinculados (ello dejando aparte un grupo misceláneo de consejos útiles, desde cómo frenar un inoportuno estornudo hasta cómo enseñar música a las monjas, pasando por las bondades del vino para mantener cierta clase de voces o la distinción entre el verdadero y el falso amigo): un primer nivel especulativo, en el que se encuadran temas como el movimiento de los astros, los poderes de los diferentes tonos, etc.; un segundo nivel relativo a la composición; por último, un tercer nivel referente a la ejecución. Los tres están conectados por múltiples lazos y, generalmente, los dos últimos aparecen mezclados, por lo que es importante distinguir entre aquello que habla de composición y aquello que habla de interpretación (un ejemplo claro se halla en lo tocante al acompañamiento, palabra que alude tanto a la línea del bajo - composición- como a su realización improvisada - ejecución-). El contexto suele explicar en qué nivel nos encontramos, y las frases o expresiones sacadas de su marco faci-

1. Los tres tratados enciclopédicos fundamentales para comprender la música española del siglo XVII son: P. CERONE, El melopeo ó Maestro, Nápoles, 1613; A. Lorente: El porqué de la música, Alcalá de Henares, Nicolás de Xamares, 1672; y P. Nassarre: Escuela música según la práctica moderna, Zaragoza, Herederos de Diego de Larumbe, 1724 y Manuel Román, 1723 (aunque publicado ya en el XVIII, su composición pertenece básicamente a los últimos años del siglo XVII). 
litan notablemente una interpretación errónea, de modo que casi cualquier frase aislada puede servir para explicar una idea preconcebida o la contraria.

Entrando ya en el tema de las voces y su uso en el canto de órgano (la música mensural; el canto llano - ejecutado por el coro, es decir, el clero de las iglesias, contrapuesto a la capilla de música - merece un estudio propio, para el que se han de tener en cuenta testimonios similares, y también se ha de reflexionar sobre las influencias del modo de cantar canto de órgano sobre el canto llano), debe comenzarse por distinguir dos ámbitos fundamentales, socialmente separados, de la práctica musical: la iglesia y el teatro. (La cámara, o la música civil no teatral, puede asimilarse al segundo por repertorio, pero a la primera por la formación técnica y procedencia de algunos ejecutantes: es el caso de José Marín, que, aparte de un personaje novelesco por su vida azarosa, es clérigo, tenor de una capilla eclesiástica y desarrolla una intensa actividad profana, de cámara o salón.) En cada uno de estos ámbitos se cantan repertorios distintos —aunque conectados-, y los ejecutantes pueden diferir considerablemente por su naturaleza, por su formación y, en principio, por sus intenciones. A este respecto, la mayor fuente de polémicas y lo que ocasionó el concurso de numerosos moralistas en la arena de la música española de XVII, fue el estrecho parentesco existente entre la música para teatro y algunos géneros practicados en las iglesias. Un villancico y un tono teatral son prácticamente lo mismo desde el punto de vista de la composición; los textos se llevan poco, aunque la temática sea diversa; ya he aludido en otro lugar ${ }^{2}$ a que las palabras de los testigos, cuando se refieren a la música de teatro, atañen claramente a la ejecución de esa música, más que a su composición -recuérdese el conocido texto de Ignacio Camargo ${ }^{3}$-; y me parece claro que lo que preocupaba a los moralistas era el hecho de que los cantores de iglesia, en los villancicos, imitaban el estilo, gracioso, expresivo, lleno de afecto, de las actrices-cantantes del teatro. En cualquier caso, los terrenos deben ser acotados para clasificar las voces según su naturaleza y escuela, y en este artículo me centraré particularmente en el mundo eclesiástico. Dejo para otra ocasión el estudio de las voces en la música teatral, apuntando solamente que, en este ámbito, predominan las voces femeninas, en papeles femeninos y masculinos, cantando los hombres sólo en partes polifónicas (los cuatros, o la parte que suele denominarse música en las fuentes); el peso de la interpretación de las actrices-cantantes recaía en los aspectos expresivos, lo que queda manifiesto en las polémicas desatadas por los moralistas como el citado Camargo, y es posible que el nivel técnico (lo que es puramente técnica vocal) quedara en un plano inferior, algo descuidado, como parece desprenderse de las abundantes críticas recogidas en relaciones efectuadas por viajeros extranjeros en España ${ }^{4}$.

2. Cfr. L.A. GonZÁlez MARín, "El teatro musical español del siglo XVII y sus posibilidades de restauración", en Anuario Musical, 48, 1993, 63-101.

${ }^{3}$ Sobre este texto (P. Ignacio Camargo, Discurso theológico sobre los theatros y comedias de este siglo, Salamanca, Lucas Pérez, 1689), que cito y comento en mi artículo mencionado (nota 1), llamó por primera vez la atención E. CoTARELO Y MORI, Bibliografía de las controversias sobre la licitud del teatro en España, Madrid, Tipografía de la Revista de Archivos, Bibliotecas y Museos, 1904, p. 122.

4. Véanse algunas consideraciones sobre la interpretación en el teatro en mi artículo "El teatro musical...", cit. A juzgar por las fuentes, la música teatral (en cuanto a escritura) es menos exigente vocalmente que la de iglesia, por lo que se refiere a tesituras, extensiones, ornamentación... Pero muchos elementos de virtuosismo quedaban en el terreno de la ejecu- 


\section{Los cantores de las iglesias}

Aludiré en primer lugar a las capillas de música convencionales, formadas exclusivamente por varones, y tomo como ejemplo los datos hoy conocidos de las capillas de música de La Seo y El Pilar de Zaragoza 5 .

La primera reflexión tiene por objeto la cantidad, el número de cantores que habitualmente intervenían en la ejecución de música. Una capilla "de provincias" rara vez utilizaba la duplicación de voces: a más cantores, se prefería componer y cantar a más partes, y esta es, en cierto modo, una novedad del siglo XVII. Tomemos como ejemplo las capillas de La Seo y El Pilar, hacia 1600 y hacia 1670 respectivamente: hacia 1600 (en época del maestro Francisco de Silos) la capilla de La Seo contaba con seis tiples adultos, cinco contraltos, cuatro tenores y seis contrabajos (bajos), más un bajonista, un corneta, dos organistas y un ayudante, además del entonador (manchador) y el organero; aparte existe una copla de ministriles. Sorprende el número de integrantes cuando frecuentemente se cantaba a cuatro, y nunca a más de ocho partes, y ello hace pensar que ejecutar la música litúrgica del XVI tardío en Zaragoza (época de Melchor Robledo) con un cantor por parte no es necesariamente lo mejor ni más adecuado.

Por su parte, la capilla de El Pilar hacia 1670 (semejante a la de La Seo en ese tiempo) cuenta con un máximo de cuatro tiples (sumando infantes y adultos), tres contraltos, tres tenores y un bajo, además de organista, arpista y cinco ministriles fijos. Este reducido número de cantores puede afrontar con éxito la ejecución de composiciones policorales, a razón de un cantor por parte, teniendo en cuenta que la escasez de bajos cantores se suple con instrumentos (bajón o violón). En muy contadas ocasiones tenemos testimonios de que una misma voz sea cantada por varias personas, $\mathrm{y}$,

ción improvisada, por lo que es imposible emitir un juicio sobre el asunto. Por otro lado, los testimonios de algunos viajeros franceses (D'Aulnoy, Brunel, Bertaut) coinciden en señalar que las actrices de teatro carecían de técnica vocal, y que utilizaban demasiada garganta o pasajes : hemos de interpretarlo como una constatación, más bien, de que su técnica era diferente de la usada en Francia en aquel tiempo, y de que la ornamentación se introducía profusamente.

5. Dejando al margen particularidades propias de diferentes ciudades o regiones, el caso de las dos iglesias principales de Zaragoza puede considerarse, si no paradigmático, sí ilustrativo. Zaragoza es, en el siglo XVII, capital de un reino (Aragón) y cabeza de la vasta Corona de Aragón (que comprende Aragón, Cataluña, Valencia y Mallorca, y todavía mantiene vínculos con los territorios del Mediterráneo - Cerdeña, Sicilia, Nápoles- dependientes entonces del monarca de las Españas); muy floreciente en el siglo XVI - se la conocía como "la harta", por su riqueza-, las crisis del siglo XVII la han empobrecido, pero el cultivo de las artes sigue asegurado y creciente, a la sombra del santuario de la Virgen del Pilar, que atrae visitantes de toda la Península y otros territorios europeos. Aunque por su situación en el interior carece del cosmopolitismo de algunas ciudades portuarias (Valencia, Sevilla), las frecuentes visitas reales, la proximidad con Francia y -relativamente-con el Mediterráneo, y la atracción devocional del templo del Pilar (aumentada en el XVII con algunos milagros cuya noticia recorre toda Europa) la convierten en una ciudad "culturalmente viva" (este anacronismo sea dicho con las máximas precauciones y consciencia). Dos iglesias, La Seo (la verdadera catedral) y El Pilar, mantienen un largo pleito por la preeminencia (zanjado por el papa en 1675 con la unión capitular de los dos templos) y compiten en el esplendor de sus edificios, retablos, pinturas, ornato en general y, también, en el cultivo de la música. Fruto de esta situación y de una buena conservación a lo largo de los siglos es el actual Archivo de Música de las Catedrales de Zaragoza (sigla internacional E: Zac, que utilizo), que recoge los fondos musicales de ambos templos (unas 14.000 composiciones de los siglos XVI-XX), entre los que figuran 1.500 obras del siglo XVII, en gran parte de producción local. Asimismo, los archivos y bibliotecas de La Seo y El Pilar aportan una abundantísima documentación sobre la práctica musical, objeto de una investigación exhaustiva por parte del Departamento de Musicología del CSIC. Las noticias aquí manejadas sobre los cantores corresponden a nuestra base de datos, realizada partiendo de Actas capitulares, Libros de Fábrica y Obrería y Libros de Común, contrastadas con los nombres y tesituras vocales de las partichelas del fondo musical mencionado. El vaciado de las Actas capitulares fue realizado casi en su totalidad por José V. González Valle, y parte de él fue publicado en la revista Aragonia Sacra. 
cuando esto se da, no se trata de una duplicación normalizada de todas las voces, sino que solamente una de ellas se duplica, mientras las demás permanecen en manos de cantores solistas; sin duda la duplicación de una voz se debe a circunstancias particulares (tal vez la debilidad de la voz de un determinado cantor, o la obligación de no dejar a ninguno sin intervenir en una pieza, o la búsqueda de un timbre peculiar, como se constata en partes tañidas por dos instrumentos). Además, aparte de las posibilidades de cada capilla, el número de cantores y ministriles que intervenían estaba perfectamente regulado por el calendario litúrgico y dotado de una provisión económica determinada, de modo que, entre los días de canto de órgano, había fiestas de a cuatro, de a ocho, etc. Por lo que respecta a la idea muy extendida de que en obras a dos o más coros el coro I era de solistas y el II o el II eran coros más masificados (coro duplicado), en un archivo tan amplio como $E$ : Zac, raras veces - sólo cuatro- encontramos pruebas de dicha práctica: tres de ellas son villancicos de Juan Pérez Roldán (*1604-† después de 1672, maestro de capilla sucesivamente en Berlanga, Málaga, la Encarnación de Madrid, Segovia, León y El Pilar de Zaragoza ${ }^{6}$ ), tal vez todos ellos procedentes de su etapa madrileña en la Encarnación (E: Zac B-3/32, a doce, con dos juegos de partichelas para el coro III, donde dice "Duplicado"; B-9/177, a ocho - de 1658, es decir, procedente de la Encarnación-, con tres juegos de partichelas para el coro II, en los que dice "D", que puede interpretarse como "Duplicado"; B-10/202, a ocho, con el coro II duplicado); la cuarta pertenece a Joseph Ruiz Samaniego, del que luego se hablará (B-46/686, a doce —en realidad a ocho—; el coro II tiene otro juego de partichelas que figura como coro III, donde se indica "Duplicado"). También en el ámbito de la catedral de Barcelona encontramos una alusión al coro duplicado, en una ocasión muy especial, cuando se reúnen varias capillas de música, dirigidas por Marcián Albareda, ante el virrey, Conde de Santa Coloma, en un oficio "a cant d'orga a vuit cors, la composició era a quatre duplicats" ". Es decir, parece que la práctica del coro duplicado era un recurso ocasional, extraordinario, y no la norma, ni siquiera la costumbre en la mayor parte de las capillas. Ocurre que el convento de la Encarnación de Madrid disponía de una de las Reales Capillas: rica y numerosa, en ella sí se daba, al menos de vez en cuando, la duplicación de partes (una sola parte ejecutada por tres y más cantores, como antaño), pero no necesariamente el coro II: esta sería una práctica del XVIII, que Francisco Valls, en su Mapa armónico, explica como uso moderno y reprobable ${ }^{8}$. No hay motivo para suponer que en el siglo XVII no gustara en España la masificación en la ejecución musical (en otros lugares hay abundantes testimonios de celebraciones con un elevadísimo número de músicos), pero se consideraba con más arte una composición a dieciséis con un músico por parte que una a cuatro con cuatro por parte. En todo caso, mandaban las circunstancias, y entre ellas la acústica o amplitud de los lugares.

Pasemos a dar un vistazo a la naturaleza y escuela de las voces:

6. Un resumen actualizado de la biografía de Juan Pérez Roldán podrá consultarse en mis artículos "Pérez Roldán, Juan" en Diccionario de la Música Española e Hispanoamericana, Madrid, ICCMU (en prensa) y en la nueva edición, próximamente disponible, de The New Grove Dictionary of Music and Musicians.

7. Cfr. J. Pavia i Simó, La música a la catedral de Barcelona durant el segle XVII, Barcelona, Fundació Salvador Vives Casajuana, 1986, 207-208.

8. F. VAlLs, Mapa armónico, ff 145-145v (este tratado se conserva manuscrito en diferentes copias; cito por el ejemplar de la Biblioteca de la Universidad de Barcelona, Ms. 783). 
Tiples

La Seo y El Pilar contaban con niños (infantes o seises) para el servicio del culto (ordinariamente, seis o siete). Vivían con el maestro de capilla, que se ocupaba de su alimento físico y espiritual. Los más aprovechables desde el punto de vista musical intervenían como tiples de la capilla de música. En ocasiones son calificados de caponcillos, pero no siempre, lo que hace suponer - con alivio - que no todos los infantes resultaban emasculados (en cualquier caso, la castración infantil era práctica prohibida pero frecuente entre las familias sin recursos, con el fin de proporcionar carrera a los hijos): del total de infantes admitidos en el siglo XVII, al menos 5 fueron caponcillos. Cada año se admitían dos o tres infantes, pero no todos terminarían dedicados al canto (los más eran simples monaguillos), de modo que la proporción de caponcillos conocidos (éstos sí para cantar, se supone) no es alta, pero tampoco muy baja.

En cuanto a los tiples adultos, hay noticia de al menos cuatro tiples capones o capados, y en ocasiones se mencionan tiples enteros (en concreto, se rechaza al menos a dos por inferioridad respecto de los capones). Los tiples enteros eran, según parece, falsetistas, como los tiples habituales en el XVI; posiblemente utilizaban una técnica de registro único (de cabeza) y se consideraban pasados ya de moda: fueron desplazados por los castrados, de voz igualmente ágil pero más poderosa y extensa.

\section{Contraltos}

Nunca se mencionan niños, sino siempre adultos -o a lo sumo adolescentes-. Probablemente han de identificarse con lo que ahora entendemos por el hautecontre francés, es decir, tenores que utilizan esporádicamente la voz de cabeza para la zona más aguda. De hecho, las capillas de El Pilar y La Seo (suprimidas en la década de 1960) han contado hasta su extinción con plazas de contralto, ejecutadas por lo que ahora denominamos tenores de amplio desarrollo hacia los agudos. Sólo tengo noticia de un contralto capado en el contexto zaragozano del XVII, a diferencia de lo que sucede en otros países contemporáneamente.

\section{Tenores}

La escritura musical para tenores es siempre considerablemente grave; de hecho, con frecuencia los tenores cantan en función de bajete o fundamento (la disposición a cuatro más frecuente no es ya SATB, sino SSAT). Existe, sin embargo, un dato sorprendente, referido a un tenor - Joseph Budría - que es contratado por El Pilar en 1669 arguyendo que "porque aún no había acabado de mudar la voz era muy buen Tenor", lo que hace suponer que sería apto para cantar papeles de contralto. 


\section{Bajos}

Se registra una casi absoluta escasez de bajos. No existe en el XVII el puesto de bajo de capilla, sino que va asociado al de sochantre (entonador y director del coro, esto es, del canto llano), aunque parece que éstos lo ejercían sólo muy ocasionalmente. Casi todas las partes de bajo en las obras donde lo hay (como he dicho, en obras a cuatro, generalmente el papel de fundamento lo lleva el tenor o bajete) carecen de texto, es decir, se tocaban con un instrumento, al parecer casi siempre con el bajón, que así mantenía su viejo papel de sostén de la polifonía a cappella. El bajón, solo, es considerado una voz, lo que resulta interesante para comprender la escritura instrumental, en combinación con las voces, en en barroco español.

Además de las capillas formadas por varones, existen también capillas compuestas exclusivamente de voces femeninas: es el caso de los conventos de monjas. En E: Zac se recoge un conjunto de composiciones de fray Manuel Correa - fraile carmelita de origen portugués, maestro de capilla de La Seo entre 1650 y su muerte en $1653^{9}$ - destinadas a un convento de monjas carmelitas; conocemos los nombres de las cantoras (las tiples Bastida, Inés y Casilda; las contraltos Teresa y Valdés; y la tenora Doña Beatriz de Mendoza), así como los instrumentos con que se acompañaban (arpa, clavicordio —-denominación española del clavicémbalo—, vihuela de arco — viola da gamba - y bajón), y las partichelas nos dicen algo sobre sus habilidades canoras y sus tesituras extremadas, más que las de los cantores de las capillas convencionales.

Los conjuntos "mixtos" (con voces masculinas y femeninas) no parecen haber sido frecuentes en la música de iglesia, por la secular separación de sexos en este ámbito y por la prohibición expresa de que las mujeres - salvo las monjas - cantaran en las iglesias. Sólo conozco un testimonio, revelado por las partichelas manuscritas de una composición de Gerónimo Vicente (fl. Barbastro, Huesca, 1600; ca. 1628, la Encarnación, Madrid; 1632-1638, en Calahorra y posiblemente El Pilar de Zaragoza; 1638-1643, Santiago; †Barbastro, $1648^{10}$ ), un Magnificat (E: Zac B-36/577): junto a nombres de hombres cantores aparece una monja, Sor Merenciana, en lo que parece ser un caso excepcional en la música eclesiástica española.

\section{Aspectos de la ejecución vocal}

En las iglesias los niños estudiaban música (cantar, echar contrapunto, etc.) desde aproximadamente los ocho o nueve años ${ }^{11}$. La formación musical era, al menos, prolongada; todos

9. Sobre Manuel Correa y su obra, cfr. especialmente J. V. GonZÁLEZ VALLE, La música en las catedrales en el siglo XVII. Los villancicos y romances de fray Manuel Correa, Barcelona, CSIC, 1997.

10. Sobre Vicente, cfr. L. A. GonZález Marín, "Vicente, Gerónimo" en Diccionario de la Música Española e Hispanoamericana, Madrid, ICCMU (en prensa).

11. Una de las pruebas de esta afirmación se halla en un célebre discurso autobiográfico del compositor Diego Pontac (1603-1654), al que luego volveremos. Sobre Pontac, cfr. A. EzQuerro EsTeban, El músico aragonés Diego de Pontac (1603-1654), maestro de capilla de La Seo de Zaragoza, Zaragoza, IFC, 1991; y P. RAmos LóPEZ, La música en la catedral de Granada en la primera mitad del siglo XVII: Diego de Pontac, Granada, Diputación Provincial-Junta de Andalucía, 1994. 
pasaban por el aprendizaje del canto, y esto influiría sin duda en la ejecución instrumental, el fraseo, la articulación, etc. Desconocemos el nivel técnico general, pero es claro que había auténticos virtuosos: aunque la mayor parte de las obras conservadas presenten una escritura llana, sabemos por los tratados que se valoraba sobremanera el echar glosas, la gala y la garganta; para conocer este estilo de ornamentación disponemos de repertorios de glosas en los libros de música práctica y además contamos con algunas - pocas - piezas que contienen ornamentaciones escritas, como las que aquí se ofrecen en los ejemplos 1, 2, 3 y 4. Los tres primeros se han extraído de una Lamentación $2^{a}$ Feria $V$ anónima (signatura E: Zac B-89/1339), y el cuarto de la Lamentación $3^{a}$ Feria $V$ de Pedro Ximénez de Luna (signatura E: Zac B-89/1338). Ambas se encuentran en un legajo que contiene además otras lamentaciones anónimas a solo, datables todas ellas entre los años 30 y 60 del siglo XVII (en concreto, la de Ximénez de Luna debe datarse de los últimos 30 ó primeros $40^{12}$ ). El ejemplo 1 recoge el inicio de la lamentación anónima, para contralto y bajo continuo (nótese que está escrita en claves altas, por lo que ha de leerse una cuarta - lo más usual-o incluso una quinta más baja ${ }^{13}$ ) y en él pueden apreciarse algunas características del tipo de construcción melódica usual en este género en la España del siglo XVII: predominio de la sucesión de grados conjuntos, presencia ocasional de pasos anómalos (la sucesión de dos semitonos diatónicos descendentes en los compases 6-7, que ocasiona en el 7 con el bajo lo que hoy denominamos una sexta aumentada que en el siglo XVII se considera, en virtud del sistema hexacordal de solmisación, un caso de mi contra fa) y reserva de las vocalizaciones ( $g a l a$ o garganta) para las cadencias (cláusulas) o para palabras con un contenido afectivo especial. En el ejemplo 2 apreciamos un tipo de escritura glosada de más elaboración, que sin duda puede dar pistas para glosar frases llanas del tipo de la que fácilmente puede extraerse de este pasaje. El ejemplo 3 es un fragmento del final de la misma lamentación, en el que se multiplican los efectos sonoros y ornamentales de la glosa con ecos y escalas (carreras) repetidas. El ejemplo 4, tomado de la lamentación de Ximénez de Luna, muestra de nuevo modos usuales de introducir la glosa, de manera progresiva, en palabras cargadas de afecto ("furoris") y en una cadencia de tipo frigio. Ha de observarse que, en glosas y pasajes de garganta escritos, es frecuente encontrar cantidades irregulares de figuras de valor reducido - escritas normalmente como semicorcheas-, que en su estricto valor exceden o no llenan la unidad de tiempo que sustituyen (por ejemplo, nueve o siete semicorcheas contra una mínima): seguramente se trata del reflejo escrito de un estilo de canto con tiempo rubato ${ }^{14}$.

El mencionado conjunto de lamentaciones conservado en $E$ : Zac, junto a otra obra a solo que presenta una ornamentación exhuberante similar (se trata del villancico de fray Gerónimo

12. Sobre P. Ximénez de Luna, de quien conocemos actividad entre 1636 y los primeros años 40 del diglo XVII, cfr. A. Ezquerro Esteban, "Jiménez de Luna, Pedro", en Diccionario de la Música Española e Hispanoamericana, Madrid, ICCMU (en prensa).

13. Acerca de las convenciones de transposición en la música española del siglo XVII pueden verse, entre otros, mis artículos "Notas sobre la transposición en voces e instrumentos en la segunda mitad del siglo XVII: El repertorio de La Seo y El Pilar de Zaragoza", en Recerca musicològica, IX-X, 1989-90, 303-325, y "Transposición", en Diccionario de la Música Española e Hispanoamericana, Madrid, ICCMU (en prensa).

14. Se alude a este fenómeno en P. CERone, El melopeo... cit., pp. 548-549. 
González $^{15}$ titulado Paxarillo que cantas, E: Zac B-94/1422), sirve para poner en duda o desmentir la afirmación, publicada repetidas veces y mantenida largo tiempo, de que las primeras lamentaciones a solo compuestas en España se deben a Miguel de Irízar (que compone a partir de los 1660) y que tal tipología toma carta de naturaleza con Vaquedano (que compone en el último cuarto del siglo XVII y comienzos del XVIII), así como la teoría de que se debe a estos autores la introducción del bel canto en España ${ }^{16}$. La colección citada de $E$ : Zac demuestra que las lamentaciones a solo se practicaban desde antes de 1650, y además con una superabundancia de glosas que supera con creces las de Vaquedano (no digamos las de Irízar, casi silábicas). Estas glosas, cuyos modelos pueden rastrearse ya en los tratados del XVI (y se repiten a lo largo del XVII), a veces parecen revelar un arcaísmo en la composición y en la ejecución, hipótesis que se ve reforzada por el hecho de que algunas de ellas (curiosamente, las dos más tardías, datables ca. 1648 y ca. 1662 respectivamente), por su ámbito estrecho (se desenvuelven en una novena), parecen compuestas para ser cantadas con la técnica de los falsetistas al uso del siglo XVI (voces muy ágiles con un solo registro, el de cabeza, y con mucha glosa o garganta - falsetista viene de fauces -). Sin embargo, la de Luna y otra muy semejante que le atribuyo, por la amplitud de su ámbito (una docena), exigen el uso combinado de los dos (o tres, según escuelas) registros de la voz, esto es, una técnica que sí podemos denominar belcantista ${ }^{17}$.

Enlazando con esta asimilación de las técnicas del bel canto encontramos la preferencia de los capones sobre los tiples enteros, manifiesta en España desde el último tercio del siglo XVI. El mismo Cerone, el tratadista de ámbito español que más noticias da sobre las voces y el modo de cantar, expone que son mejores las voces de pecho que las de cabeza (signo de que los falsetistas habían pasado de moda), pero reconoce después que son aún mejores las que combinan los dos registros ${ }^{18}$. Para Cerone, "la boz perfecta, es juntamente alta, clara, rezia, y suave: alta para

15. Sobre fray Gerónimo González de Mendoza (fl. Madrid [convento de las Descalzas Reales] 1633-Sevilla [convento de Carmelitas] 1661), véase mi artículo "González, Gerónimo”, en Diccionario de la Música Española e Hispanoamericana, Madrid, ICCMU, 1999ss. El villancico Paxarillo que cantas, destinado a un tiple solo (el cantor que precisa la fuente es un tal fray Benito, posiblemente un capón), remeda, con una gran carga de gala que va de principio a fin del estribillo, el canto de las aves canoras.

16. Estas teorías han sido sostenidas principalmente por J. LóPEZ-CALo ("La música religiosa en el barroco español. Orígenes y características generales", en La Música en el Barroco, Oviedo, Universidad de Oviedo 1977, 147-189; Historia de la música española. 3. Siglo XVII, Madrid, Alianza, 1983; "Las lamentaciones solísticas de Miguel de Irízar y de José de Vaquedano. Un estudio sobre la melodía barroca española", AnM, 43, 1988, 121-162) y C. Villanueva Abelairas ("Las «Lamentaciones» de Semana Santa de fray José de Vaquedano (1642-1711), Maestro de Capilla de la Catedral de Santiago", Compostellanum, XXIII, 1978, 247-280; Las Lamentaciones de Semana Santa de Fray José de Vaquedano, Santiago de Compostela, Universidad de Santiago de Compostela, 1990).

17. Debe introducirse aquí un elemento de discusión sobre la conveniencia o no del término bel canto, que usa López-Calo por dependencia de la musicología alemana y anglosajona. Es un término anacrónico, que no aparece siquiera en Tosi (1723) ni Giovanni Mancini (1774), acuñado a mediados del siglo XIX para referirse al modo de cantar en los siglos XVIII y comienzos del XIX, con bella voz natural, buena escuela para la agilidad, maestría de estilo y fusión de los registros vocales (cfr. O. JANDER, "Bel canto" en The New Grove Dictionary of Opera, London Macmillan, 1992; y el interesantísimo trabajo de R. JACOBS La controverse sur le timbre du contre-ténor, Arlés, Hubert Nyssen Ed., 1985). La musicologia alemana de la primera mitad de siglo (Haas, Bukofzer) usó el término para referirse al lirismo de la ópera veneciana y la cantata romana de los años 30-40 (Cavalli, L. Rossi...) como contraste con el viejo stile rappresentativo. El término, anacrónico como es, puede ser útil para diferenciar el modo de cantar con fusión de registros del viejo estilo de registro único. En este sentido, las opiniones de René Jacobs son particularmente respetables, dado que une a la investigación la práctica musical como vehículo empírico de conocimiento científico.

18. P. Cerone, El melopeo..., cit., especialmente pp. 67-73, 325-331, 478-481 y 504-564. 
que sea suficiente, y bastante en los puntos altos y subidos; clara para que hinche los oydos; rezia, para que no falte calando las bozes, mas siempre sea llena y justa en su cantidad: y suave, para que no martirize los oydos, mas antes mitigue y adulcifica las orejas de los oydores... aquella que es ygual, clara, suave, rezia (pero humana; es a saver, dulce y no estruenda a modo de la voz de los brutos animales) limpia, alta y baxa." 19

Hay dos testimonios escritos, bien conocidos pero nunca suficientemente sometidos a reflexión y discusión, que nos hablan directamente de lo que se consideraba un modo de cantar admirable dentro del mundo eclesiástico. Me refiero a las cartas cruzadas en 1633 entre Diego Pontac y el racionero Manuel Correa del Campo (que no es el fray Manuel Correa antes mencionado, sino un músico de igual nombre activo en la catedral de Sevilla por los mismos años) en que ambos se erigen en paladines de sendas monjas cantoras ${ }^{20}$, una del convento de San Clemente de Granada (la defendida por Pontac, a la que califica de "Serafina" ${ }^{21}$ ) y otra del convento de Santa Paula de Sevilla (la favorecida por Manuel Correa, de nombre Margarita). He aquí lo que dice Pontac de la "Serafina":

"hallé en la ciudad de Sevilla en el Convento Real de San Clemente una muger, mal dixe, un Ángel, un Serafín, con cuya buena voz de buen metal, larga en estremo la garganta, yo no sé dezir cómo era, y cierto que con tratar esta professión desde nueve años hasta treynta que hoy tengo, y haber oydo en Madrid, Zaragoza y Valladolid, y en otras Capillas Reales tantos y tan excelentes como tiene Su Magestad, que cantan, todo es sombra deste cuerpo; y comparalla con todo lo mejor es, de conocido, hazella agravio: tantos passages tan bien hechos, tantos altos, tan soberanos quiebros, tan lindo declarar de letra, tan gran perfección en dar y alçar, tal mesura en el rostro, tal descanso en cuanto haze, no es posible haya fuera del Cielo, quien la imite. Y si Su Magestad llega a entender cosa tan grande como es esta Serafina, y sus tres compañeras, tengo por cierto la han de mandar llevar, con buleto de Su Santidad, a algún convento de Madrid, donde todos cuantos maestros hay en el mundo gocen cosa tan grande, y me ayuden a dar gracias a Dios por lo mucho que depositó en esta Serafina, que Dios guarde, etc...."

La respuesta de Manuel Correa es más extensa y algo menos precisa en su defensa musical de su cantante favorita, doña Margarita. Nombra a muchos cantores portugueses, a los que considera superiores a los españoles. De doña Margarita dice que "es su voz excelentíssima de agradable suabidad, la glossa, y passages de garganta bien granada, lisa, y veloz, con requebrados, y blandos quiebros (es la consistencia del quiebro, ablandar, y quebrar, la sequedad y aspereza de la voz, su efecto, regalar y suavizarse no violentarse y enfurecerse a tirar punzadas, y saetas al sentido del oyente[)]. Es artificioso elegante y dulcísimo el asseo de su cantar en el modo, y galantería..."; tenía una voz firme apta para "no despeñarse de los puestos difíciles", además de "natural gala", y se acompañaba con un instrumento al cantar. En resumen, Pontac valora los

19. Ibid., pp. 325-326.

20. El discurso de Pontac y la respuesta de Correa se encuentran, impresos, en la Biblioteca Nacional de Lisboa (F.G. 2266 olim Ms. H. 6. 38), así como en copia manuscrita de F. Asenjo Barbieri en su legado conservado en la Biblioteca Nacional de Madrid (Ms. 14.069). Los textos se han reproducido varias veces, la más reciente en el trabajo de P. RAMOS LÓPEZ, La música..., cit., pp. 325-328, que comenta también algunos aspectos (pp. 204-207) de lo que denomina "la melodía auténticamente barroca, la típica del bel canto", utilizando el término en el sentido que le da López-Calo, a quien critica.

21. Según P. Ramos se trata del nombre de la monja, pero creo que más bien es sólo un calificativo elogioso. 
pasajes o vocalizaciones (la glosa de garganta o gala), los agudos, los ornamentos (quiebros), la inteligibilidad y expresión del texto, la sensación de ausencia de esfuerzo y el hecho de no descomponer el gesto (algo en lo que insistía Cerone), y un punto más difícil de explicar: la "perfección en dar y alçar", que interpreto como sujeción al compás (más bien al tactus, a la unidad de tiempo) sin perder el buen aire o airecillo de que hablan algunos tratadistas españoles ${ }^{22}$. Manuel Correa alaba de doña Margarita la dulzura de su voz, lo sensual de sus ornamentos, su habilidad - y velocidad - para la glosa.

Hasta aquí este pequeño avance de nuestros trabajos en curso. La investigación sobre los elementos de la práctica musical en la España del siglo XVII está, todavía, en mantillas. Una reflexión razonada sobre los datos y elementos de juicio que aquí se presentan debe coordinarse con un estudio serio sobre otros aspectos de la ejecución musical, como los diapasones en uso en la España del siglo XVII, o las posibles pervivencias de prácticas antiguas en algunas tipologías de la música de tradición oral superviviente — como las saetas - fenómeno que nos obliga a replantearnos el tema de la tan traída y llevada "ruptura de tradición", lugar común a la hora de abordar modernamente la recuperación de prácticas musicales históricas, pero que no siempre puede sostenerse de modo convincente en el caso de la música eclesiástica española. Algunas obras y/o géneros procedentes de los siglos XVI-XVIII han pervivido como música viva de repertorio en las capillas de música españolas, las cuales recibieron golpes mortales en el siglo XIX (desde la invasión napoleónica a las guerras carlistas, las desamortizaciones o el Concordato de 1851 - que impedía a los seglares ejercer de cantores, organistas o maestros de capilla-, o el auge de los géneros devocionales y del fenómeno orfeonístico popular) pero no dejaron de existir hasta muy recientemente: aún viven algunos de los últimos cantores y maestros de capilla de La Seo de Zaragoza (el que fuera maestro de capilla de esta catedral, Jaime Sirisi, me explicó hace algún tiempo cómo él en persona, como elemento de modernidad, abolió el uso del fagot -que ya sustituía al viejo bajón- en la polifonía a cappella en la década de 1950!). La musicografía del XIX español nació o se crió en las capillas de música, donde todavía se tocaban chirimías y bajones y se cantaba música de Robledo y Guerrero, y en estas capillas se gestaron los conservatorios y escuelas de música en España, de modo que la situación musical en la España actual es todavía resultado de los últimos y decadentes momentos de la tradición musical eclesiástica española, que ahora se extingue ya. Esta circunstancia, junto con el hecho constatable de que algunas manifestaciones de música popular (en España y zonas dominadas por su cultura, como la América latina) también deben considerarse como epígonos - muy contaminados tal vez por el tiempo y diversas influencias - de la tradición culta española de los siglos XVI-XVIII, exige una mayor coordinación entre la musicología histórica y la denominada etnomusicología, con vistas a un mejor conocimiento y a la deseable restauración, de cara al público -ávido de nueva música antigua —, del patrimonio musical español.

22. Me refiero a T. de SAnCta María (Arte de tañer fantasía, Valladolid, Francisco Fernández de Córdova, 1565) y F. Correa de Arauxo (Facultad orgánica, Alcalá de Henares, 1626), que explican diversos modos de introducir la desigualdad en grupos de figuras iguales, en una especie de tempo rubato regularizado dentro del tactus. El último debe ser tenido muy en cuenta a la hora de comprender los quiebros, redobles y demás ornamentos, pues pertenece a la misma época y contexto de las cartas de Pontac y Manuel Correa. 
Ejemplo 1:

1

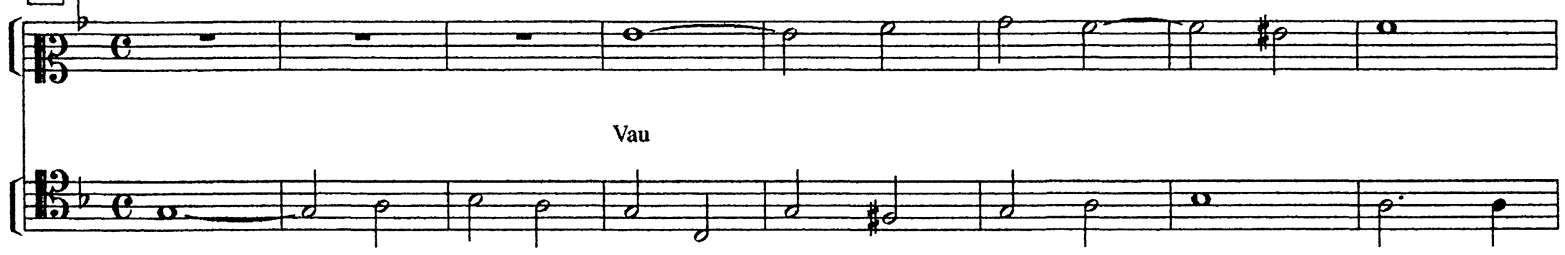

9

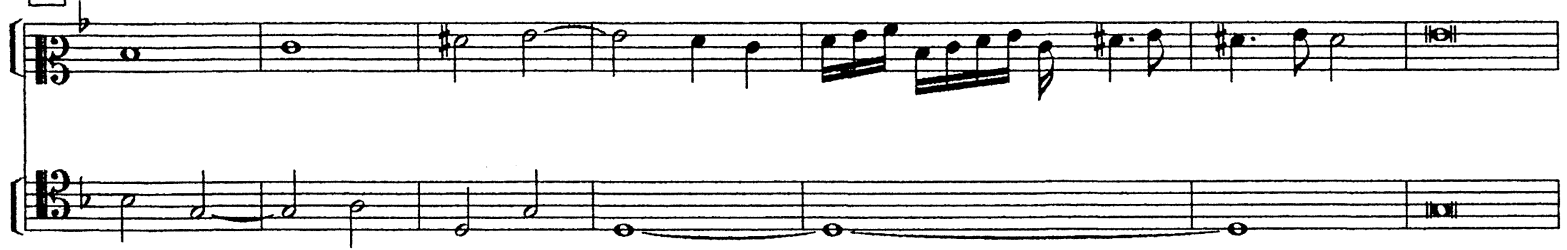

\section{Ejemplo 2:}
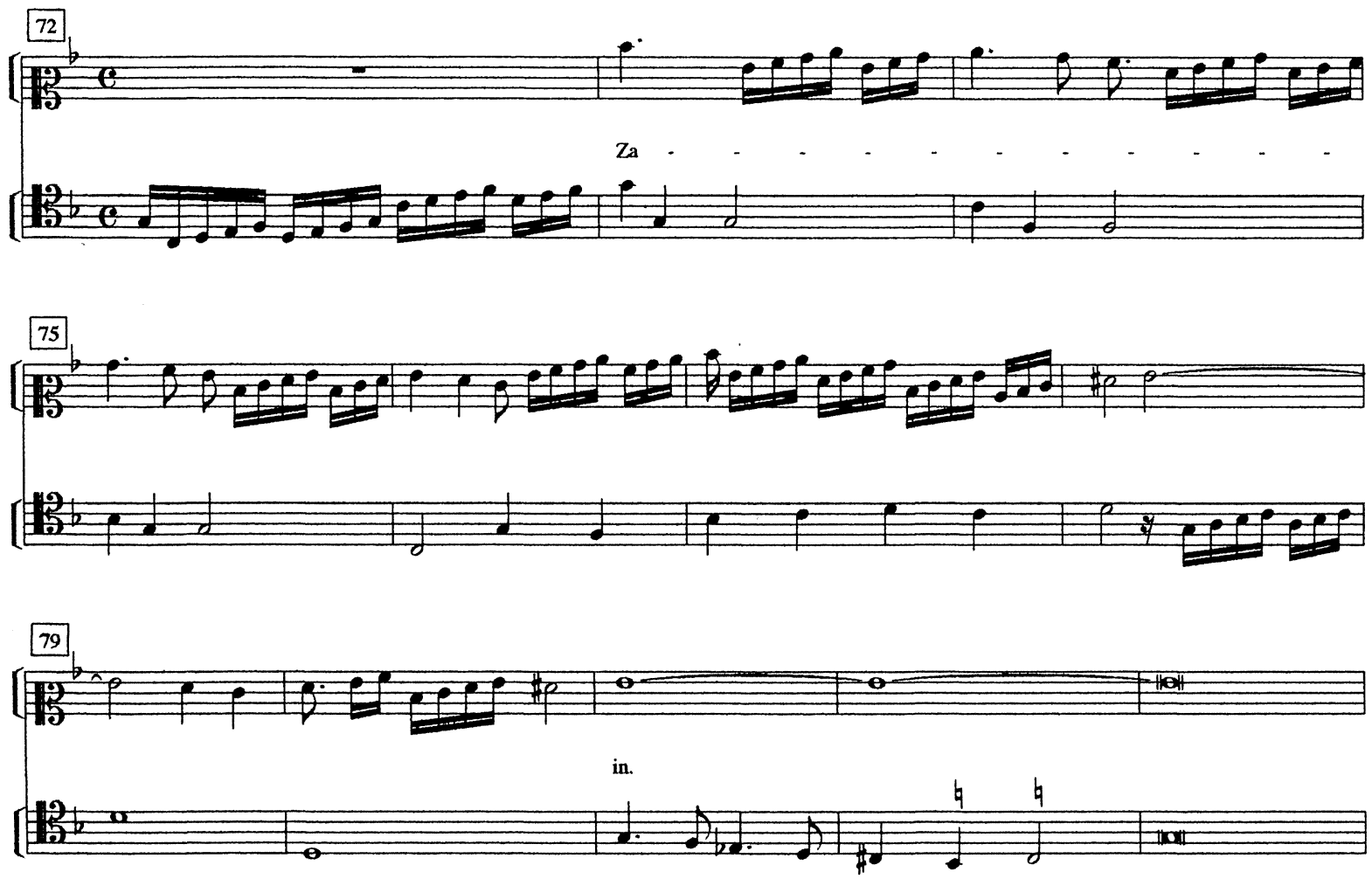

94

(c) Consejo Superior de Investigaciones Científicas Licencia Creative Commons 3.0 España (by-nc)
Anuario Musical, 56 (2001)

http://anuariomusical.revistas.csic.es 
Ejemplo 3:

171
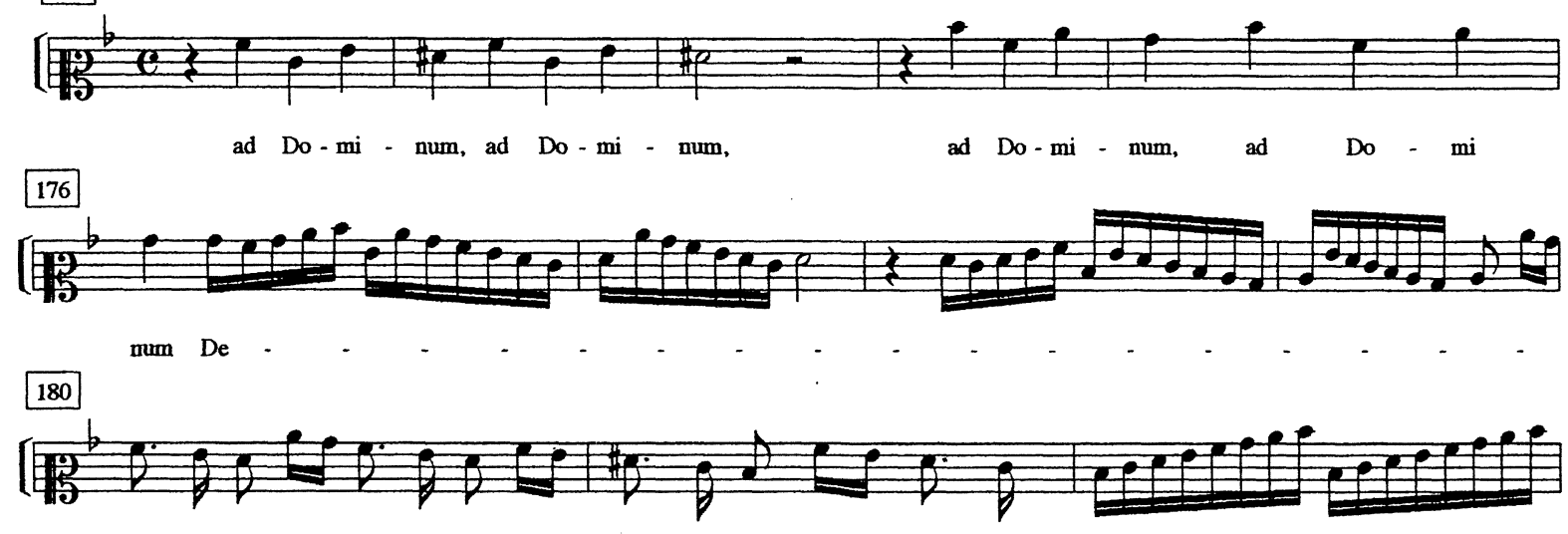

Ejemplo 4:

139

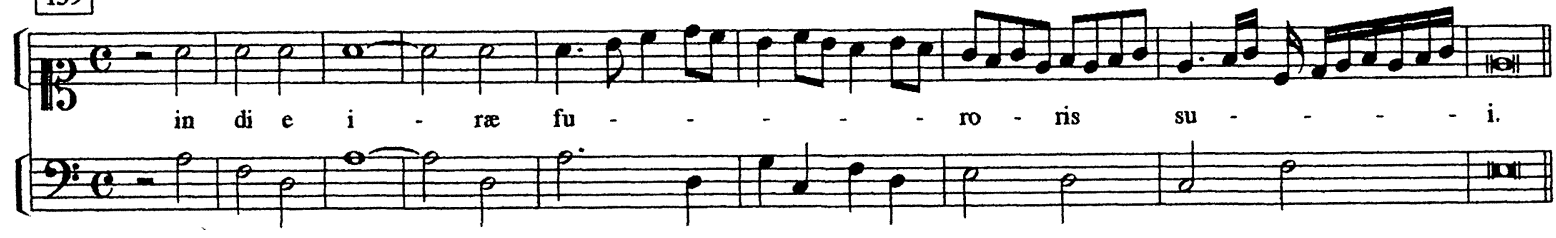

